\title{
Understanding the Increasing Hot Extremes over the Northern Extratropics Using Community Atmosphere Model
}

\author{
Siyu Zhao ${ }^{1}$ (1) Jiaying Zhang ${ }^{2} \cdot$ Yi Deng $^{3} \cdot \mathrm{Na} \mathrm{Wang}^{3,4}$
}

Received: 7 June 2021 / Revised: 6 September 2021 / Accepted: 7 October 2021 / Published online: 18 October 2021

(c) The Author(s) 2021

\begin{abstract}
The past four decades have seen an increase of terrestrial hot extremes during summer in the northern extratropics, accompanied by the Northern Hemisphere (NH) sea surface temperature (SST) warming (mainly over $10^{\circ}-70^{\circ} \mathrm{N}, 0^{\circ}-360^{\circ}$ ) and $\mathrm{CO}_{2}$ concentration rising. This study aims to understand possible causes for the increasing hot extremes, which are defined on a daily basis. We conduct a series of numerical experiments using the Community Atmosphere Model version 5 model for two periods, 1979-1995 and 2002-2018. The experiment by changing the $\mathrm{CO}_{2}$ concentration only with the climatological SST shows less increase of hot extremes days than that observed, whereas that by changing the NH SST (over $10^{\circ}-70^{\circ} \mathrm{N}, 0^{\circ}-360^{\circ}$ ) with constant $\mathrm{CO}_{2}$ concentration strengthens the hot extremes change over mid-latitudes. The experiment with both SST and $\mathrm{CO}_{2}$ concentration changes shows hot extremes change closer to the observation compared to the single-change experiments, as well as more similar simulations of atmospheric circulations and feedbacks from cloud and radiative processes. Also discussed are roles of natural variability (e.g., Pacific Decadal Oscillation and Atlantic Multidecadal Oscillation) and other factors (e.g., Arctic sea ice and tropical SST).
\end{abstract}

Keywords Hot extremes · Sea surface temperature · Greenhouse warming · Community Atmosphere Model · Climate change $\cdot$ Natural variability

\section{Introduction}

Although the increase of the global mean temperature has slowed down since the late 1990s (Kosaka and Xie 2013), terrestrial hot extremes characterized by extreme high surface air temperature (SAT) have become more frequent in recent decades (Perkins-Kirkpatrick and Lewis 2020). Since the twenty-first century, severe summer hot extremes over

Communicated by Jin-Ho Yoon.

Siyu Zhao

siyu_zhao@atmos.ucla.edu

1 Department of Atmospheric and Oceanic Sciences, University of California, Los Angeles, Los Angeles, CA, USA

2 School of Civil and Environmental Engineering, Georgia Institute of Technology, Atlanta, GA, USA

3 School of Earth and Atmospheric Sciences, Georgia Institute of Technology, Atlanta, GA, USA

4 Shandong Climate Center, Shandong Province Meteorological Bureau, Jinan, Shandong, China the northern extratropics have been frequently observed, such as the ones in Europe in 2003 (Schär and Jendritzky 2004), Russia in 2010 (Coumou and Rahmstorf 2012), United States in 2011 (Luo and Zhang 2012), and China in 2013 and 2015 (Sun et al. 2016; Ma et al. 2017). These hot extremes resulted in severe damages to ecosystems and human society, including forest fires, decreasing agricultural production, and loss of human life (e.g., Ciais et al. 2005; Coumou and Rahmstorf 2012). Indeed, some hot extremes were concomitant with droughts due to strong anti-correlation between temperature and precipitation during summer over the extratropics (Coumou et al. 2018). Due to disastrous impacts of hot extremes and accompanying droughts, there is an urgent need for better understanding the dynamics and physics linked to these extremes.

Hot extremes are usually linked to large-scale circulation anomalies driving subsidence of air mass (Röthlisberger and Martius 2019; Tian et al. 2020), cloud changes that modulate the surface radiation (Jaeger and Seneviratne 2011; Sousa et al. 2018; Tian et al. 2020), and/or enhanced warm air advection (Sousa et al. 2018). For example, a circumglobal teleconnection (CGT) pattern, characterized by a 
zonal wavenumber-5 structure from an empirical orthogonal function (EOF) analysis, results from internal atmospheric dynamics and provides the major source of climate variability and predictability in northern mid-latitudes, especially for U.S. hot extremes (Teng et al. 2013). Ding and Wang (2005) suggested that the maintenance of the CGT pattern depends on interactions between the CGT (i.e., Rossby wave train patterns) and Indian summer monsoon (related to the west-central Asian high). Such CGT pattern was also identified through a self-organizing map (SOM) analysis and tends to be linked to the increasing hot extremes over the Northern Hemisphere (NH) (Lee et al. 2017).

These proximate drivers can be connected to atmospheric chemical composition and sea surface temperature (SST) (e.g., Lenderink et al. 2007; Trenberth et al. 2015; Xie et al. 2015; Horton et al. 2016; Baker et al. 2018). For example, the decadal change of the daytime, nighttime, and compound hot extremes over China is attributed to effects of anthropogenic forcing, such as those related to greenhouse gas concentrations and anthropogenic aerosol emissions ( $\mathrm{Su}$ and Dong 2019). The change in global SAT from 1970 to 2000 s is associated with anthropogenic forcing, in combination with the effect of surface-atmosphere interactions and large-scale circulation changes (Tian et al. 2020). Furthermore, the increase of summer hot extremes over the NH land is linked to the Atlantic Multidecadal Oscillation (AMO) (or an AMO-like SST pattern) (Johnson et al. 2018; Gao et al. 2019), but the Atlantic SST forced trend in daily maximum SAT (over land) during 1979-2012 is much weaker in magnitude than that observed (Johnson et al. 2018). SST effects on hot extremes (or global SAT) have also been documented in other studies (e.g., Kosaka and Xie 2013; Watanabe et al. 2014; Dai et al. 2015; Stolpe et al. 2017; Dai and Bloecker 2019).

Many studies have applied an atmospheric general circulation model (AGCM) to understand roles of atmospheric composition (e.g., $\mathrm{CO}_{2}$ concentration) and SST in the change of atmospheric circulations. For example, Deser and Phillips (2009) applied the Community Atmosphere Model version 3 (CAM3) model to examine the relative roles of direct atmospheric radiative forcing (e.g., changes in well-mixed greenhouse gases) and observed SST change in global atmospheric circulation trends during boreal winter for 1950-2000. Their results showed that atmospheric radiative changes slightly contribute to circulation trends over the Atlantic-Eurasian sector in the NH, while the SST change largely contributes to the intensification of the Aleutian low. In addition, some studies compared circulation responses to quadrupled atmospheric $\mathrm{CO}_{2}$ concentration and to $4 \mathrm{~K} \mathrm{SST}$ warming using Atmospheric Model Intercomparison Project (AMIP) runs (e.g., Grise and Polvani 2014; Shaw and Voigt 2015 , 2016). For example, during summer, $\mathrm{CO}_{2}$ concentration rising and SST warming can result in opposite effects on atmospheric circulation change (Shaw and Voigt 2015). This tug of war on circulations highlights the importance of understanding the effect of $\mathrm{CO}_{2}$ concentration and SST on hot extremes, which are closely tied to circulations.

Based on previous studies that applied the AGCM to examine the roles of atmospheric composition and SST in atmospheric circulations, our study adopts a similar approach to understand their individual and combined effects on terrestrial hot extremes during boreal summer over the northern extratropics. We conduct numerical experiments using CAM version 5 (CAM5) model to investigate how observed $\mathrm{CO}_{2}$ change and observed SST change influence the change of hot extremes in recent decades.

\section{Data and Methodology}

\subsection{Data}

Daily mean observed geopotential height, wind, total-cloud cover, and surface downward shortwave and longwave radiations (hereafter SW and LW, respectively) are from the European Centre for Medium Range Weather Forecasts Reanalysis 5 (ERA5) on $2.5^{\circ} \times 2.5^{\circ}$ spatial grids (Copernicus Climate Change Service 2017). Daily mean 2-m air temperatures is from ERA5 with a resolution of $1.0^{\circ}$ and from the National Centers for Environmental Prediction (NCEP)-National Center for Atmospheric Research (NCAR) reanalysis with a Gaussian grid (Kalnay et al. 1996). The ERA5 and NCEP-NCAR data cover the boreal summer (June-August) for the period of 1979-2018 and 1950-2018, respectively. The monthly mean SST and sea ice concentration (SIC) come from the Hadley Centre Sea Ice and Sea Surface Temperature datasets (HadISST) on $1.0^{\circ} \times 1.0^{\circ} \mathrm{spa}-$ tial grids for the period of 1950-2018 (Rayner et al. 2003).

\subsection{Observed Hot Extremes}

At each grid point over the northern extratropics $\left(20^{\circ}-80^{\circ} \mathrm{N}\right.$, $0^{\circ}-360^{\circ}$; over land), we define an anomalous hot day when the daily $2-\mathrm{m}$ temperature at the grid point is above $90^{\text {th }}$ percentile for that calendar day over the period of 1979-2018 (Zhao et al. 2017, 2020). Such classifications are performed for all days and the total number of days of hot extremes in summer is computed for each year. We also use another method to define anomalous hot days by comparing the daily 2-m temperature anomaly (deviation from long-term daily climatology) with the 1.5 standard deviation in daily temperature for that calendar day. The composite anomalies for an early/late period (which will be defined later) are calculated by subtracting the summer climatology from the average of the annual data over that period, with the Student's $t$ test applied to examine the significance. 


\subsection{CAM5 Experiments}

To investigate the individual and combined effects of $\mathrm{CO}_{2}$ concentration and SST on hot extremes, we apply the NCAR CAM5 model (Neale et al. 2012), with a grid of $1.9^{\circ} \times 2.5^{\circ}$ (gx1v6) for atmosphere (ocean) and 30 vertical levels in the atmosphere. The control experiment is forced with the climatological SST and $\mathrm{CO}_{2}$ concentration (Table 1). Other factors (e.g., SIC) that may contribute to hot extremes are set as climatology. The model has been validated by comparing the climatological SAT over land in the Control Exp with that observed. Three sets of sensitivity experiments are conducted with each set including an "early" run, a "transition" run, and a "late" run. The transition run is forced with the climatological SST and $\mathrm{CO}_{2}$ concentration. The early and late runs are forced with different combinations of SST and $\mathrm{CO}_{2}$, similar to the setting in Deser and Phillips (2009). For example, in the FULL Exp, the SST for the early and late runs is the SST climatology plus monthly mean $\mathrm{NH}$ SST anomaly $\left(10^{\circ}-70^{\circ} \mathrm{N}, 0^{\circ}-360^{\circ}\right)$ averaged for early (1979-1995) and late (2002-2018) periods, respectively; and the $\mathrm{CO}_{2}$ for the early and late runs is the averaged $\mathrm{CO}_{2}$ concentration in the early and late periods, respectively.

To be comparable to the observation, the early and late runs are integrated forward for 22 years with the first 5 years discarded as spin-up, and the transition run is integrated forward for 11 years with the first 5 years discarded (Fernando et al. 2016). Thus, each set of sensitivity experiments includes 40 members, with 17 ensembles in early runs (corresponding to the 17 years in the early period), 17 in late runs (for the late period), and 6 in the transition run (for the transition period). The definition of hot extremes in each set of sensitivity experiments is similar to that observed, i.e., by comparing the daily SAT with $90^{\text {th }}$ percentile for that calendar day among all members (total of 40 in each set). The composite anomaly for an early (late) run in each set is calculated by subtracting its 40 -member average from the average of the 17 ensembles of the early (late) run in that set.

\section{Results}

\subsection{Decadal Change of Hot Extremes}

Figure 1a shows the linear trend of the total number of days (using the ERA5 dataset and the definition of exceeding the $90^{\text {th }}$ percentile) of hot extremes over the northern extratropics during the period of 1979-2018. The linear trend has the largest magnitudes over five key regions: Europe $\left(35^{\circ}-60^{\circ} \mathrm{N}\right.$, $\left.10 \mathrm{~W}^{\circ}-50^{\circ} \mathrm{E}\right)$, northern Africa-western Asia $\left(20^{\circ}-35^{\circ} \mathrm{N}\right.$, $\left.18 \mathrm{~W}^{\circ}-65^{\circ} \mathrm{E}\right)$, eastern Asia $\left(20^{\circ}-60^{\circ} \mathrm{N}, 95^{\circ}-135^{\circ} \mathrm{E}\right)$, western North America $\left(20^{\circ}-45^{\circ} \mathrm{N}, 95^{\circ}-125^{\circ} \mathrm{W}\right)$, and Greenland $\left(60^{\circ}-80^{\circ} \mathrm{N}, 15^{\circ}-70^{\circ} \mathrm{W}\right)$. Such a trend bears a strong resemblance to the observed trend in daily maximum SAT in Johnson et al. (2018). The domain-averaged anomalies of hot extremes days and SAT (over land) have a positive trend (significant at the 0.01 level), with the positive anomaly of hot extremes days from 2002 (Fig. 1b). The increase of the extremes is not sensitive to either the definition of extremes or dataset applied. Hence, the ERA5 dataset and the definition of exceeding the $90^{\text {th }}$ percentile are used in the following analyses. The early period and late period are defined as 1979-1995 and 2002-2018, respectively, with a transition period during 1996-2001. There are more hot extremes in the late period and this difference is statistically significant at the 0.05 level over the five key regions (Fig. 2a).

\subsection{Role of $\mathrm{CO}_{2}$ Change}

First, we conduct the CAM5 experiment by changing the $\mathrm{CO}_{2}$ only with climatological SST $\left(\mathrm{CO}_{2} \mathrm{Exp}\right)$. The spatial distribution of the extremes is either spatially shifted over the eastern Asia and western North America or insignificant over Europe, northern Africa-western Asia, and Greenland (Fig. 2b). The domain averaged anomaly of hot extremes days in the $\mathrm{CO}_{2}$ Exp is obviously smaller than that observed for the northern extratropics and five key regions (Fig. 3a),
Table 1 List of main CAM5 experiments. There are three sets of the sensitivity experiments. Each experiment includes an early run, a transition run, and a late run. "Clm" denotes climatology of $1979-2018$

\begin{tabular}{lllll}
\hline Experiments & Runs & Ensembles & SST & $\mathrm{CO}_{2}$ \\
\hline Control Exp & $\backslash$ & 17 & $\mathrm{Clm}$ & $\mathrm{Clm}$ \\
$\mathrm{CO}_{2}$ Exp & Early & 17 & $\mathrm{Clm}$ & Early \\
& Transition & 6 & $\mathrm{Clm}$ & $\mathrm{Clm}$ \\
& Late & 17 & $\mathrm{Clm}$ & Late \\
NH-SST Exp & Early & 17 & $\mathrm{Clm}+\mathrm{NH}$ SST anomaly (early) & $\mathrm{Clm}$ \\
& Transition & 6 & $\mathrm{Clm}$ & $\mathrm{Clm}$ \\
& Late & 17 & $\mathrm{Clm}+\mathrm{NH}$ SST anomaly (late) & $\mathrm{Clm}$ \\
FULL Exp & Early & 17 & $\mathrm{Clm}+\mathrm{NH}$ SST anomaly (early) & Early \\
& Transition & 6 & $\mathrm{Clm}$ & Clm \\
& Late & 17 & $\mathrm{Clm}+$ NH SST anomaly (late) & Late \\
\hline
\end{tabular}


Fig. 1 a Linear trend of the total number of days of hot extremes (shading; days per year) for the period of 1979-2018. Black boxes indicate the five key regions. b The domain averaged $\left(20^{\circ}-80^{\circ} \mathrm{N}, 0^{\circ}-360^{\circ}\right.$; over land) anomaly of the total number of days of hot extremes defined by $90^{\text {th }}$ percentile using ERA5 dataset, 1.5 standard deviation using ERA5 dataset, and $90^{\text {th }}$ percentile using NCEP-NCAR dataset, and the domain averaged (over land) summer mean SAT $\left({ }^{\circ} \mathrm{C}\right)$ using ERA5 from 1979 to 2018 . c Difference in summer mean SST $\left({ }^{\circ} \mathrm{C}\right)$ between the late and early periods in the observation. Stippling in $\mathbf{a}$ and $\mathbf{c}$ indicates regions significant at the 5\% level according to the Student's $t$-test
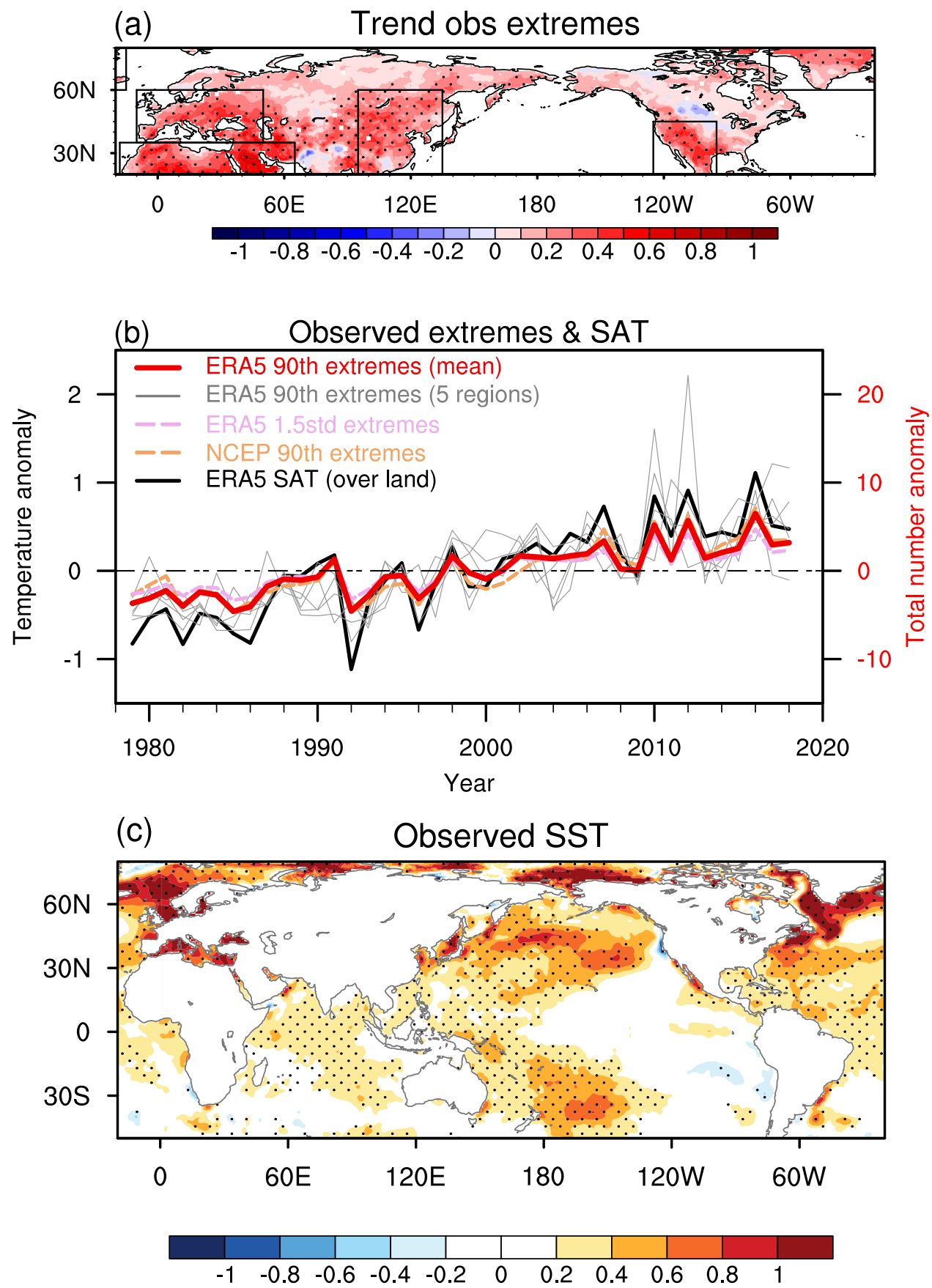

consistent with the smaller magnitude of the anomaly in the spatial map.

We further examine dynamic and thermodynamic factors associated with hot extremes. In the observation, the summer mean flow shows a positive geopotential height anomaly at $300 \mathrm{hPa}$, with high-pressure centers over the eastern Europe, mid-latitude eastern Asia, eastern Siberia, west coast of North America, and Greenland (Fig. 4a; shading). The hemispheric-scale circulation anomaly with the zonal wavenumber- 5 structure bears some similarity with the CGT pattern identified in Teng et al. (2013) and Lee et al. (2017). This result indicates the dominant role of the CGT pattern in the summertime temperature variability over the northern extratropics. Observed synoptic eddy kinetic energy (EKE; Zhao et al. 2020) based on 2.5-6-day bandpass-filtered daily winds shows a reduction over mid- and high-latitudes (Fig. 4a; contours), indicating a weakening of fast-moving Rossby waves (Coumou et al. 2015, 2018). The relationship between eddy and mean flows, i.e., high pressure anomaly versus low EKE anomaly, can be understood via a non-modal instability analysis (Zhao et al. 2018, 2020; Zhao and Deng 2020; Mak et al. 2021). Figures 5a and 
Fig. 2 a Difference in the total number of days of hot extremes (shading; days) between the late and early periods in the observation. b-d Same as in a, but between the late and early run in three sets of CAM5 experiments. Stippling indicates regions significant at the 5\% level according to the Student's $t$-test. Black boxes indicate the five key regions (a)

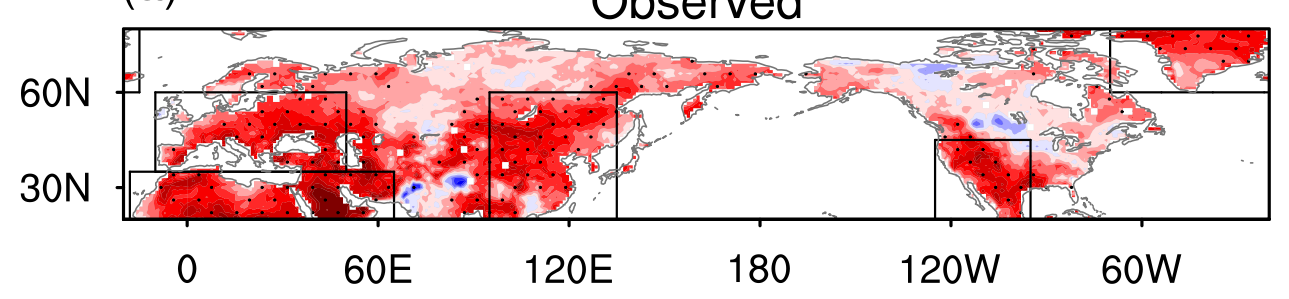

(b)

$\mathrm{CO}_{2} \operatorname{Exp}$
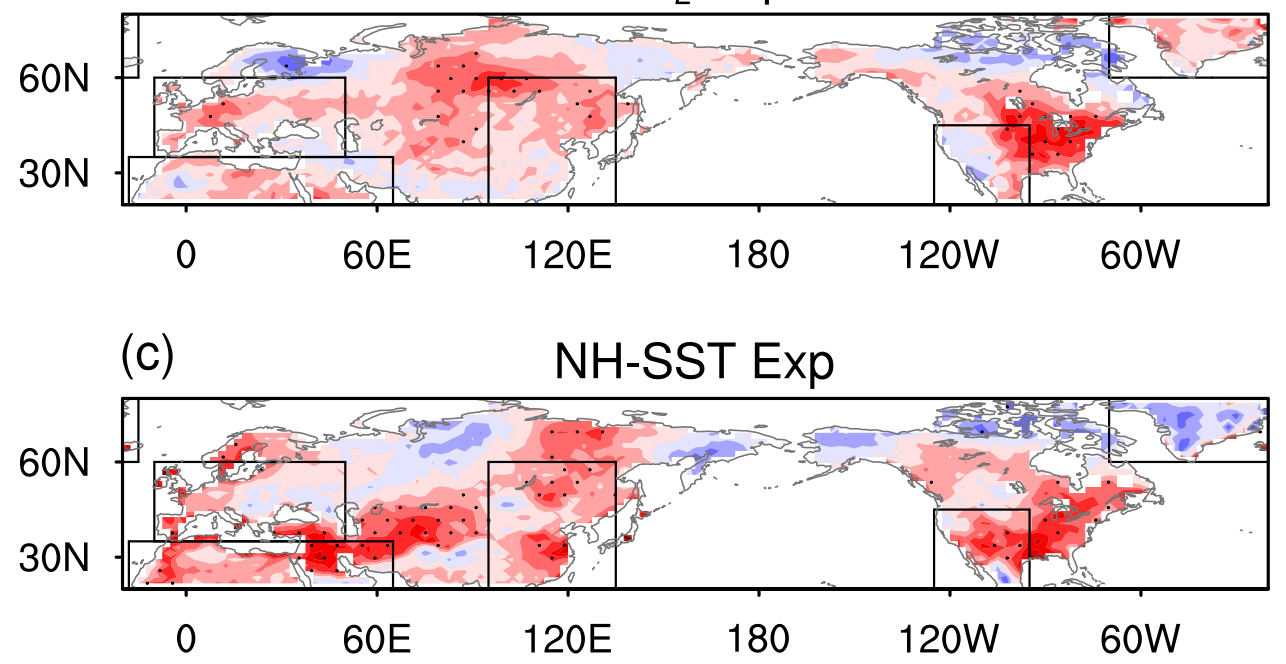

(d)
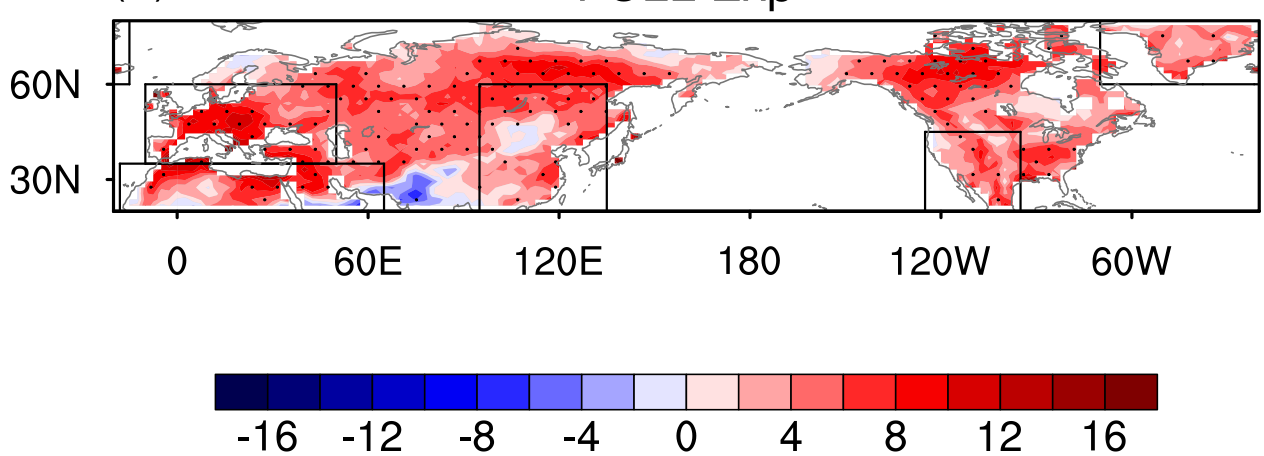

6a show observed anomalies of total-cloud cover, SW and $\mathrm{LW}$, which can act as feedbacks to circulation changes.

In the $\mathrm{CO}_{2}$ Exp, the magnitude of geopotential height anomaly over the northern extratropics is underestimated (Fig. 4b), accompanied by a misrepresentation of totalcloud cover, SW and LW anomalies, especially over the five key regions (Figs. 5b and 6b). For example, over Europe, the magnitude of upper-level geopotential height and synoptic EKE anomalies is much smaller compared to that in the observation. The weak high pressure and strong synoptic activity (characterized by positive synoptic EKE anomaly) lead to more frequent maritime air masses movement, creating a wet and cool condition over Europe.
The total-cloud cover and surface downward radiations anomalies are also small in magnitude. The large difference between the observation and $\mathrm{CO}_{2}$ Exp can be also seen in domain averaged fields (Fig. 3). The magnitude of the domain averaged variables (blue bars) is generally smaller than that in the observation for the northern extratropics and five key regions. The reason for the difference is probably because the SST is set as climatology in the $\mathrm{CO}_{2}$ Exp. As we know, the majority of excess heat in the Earth system due to rising greenhouse gases (e.g., $\mathrm{CO}_{2}$ ) concentration ends up in oceans (e.g., von Schuckmann et al. 2020). 
(a)

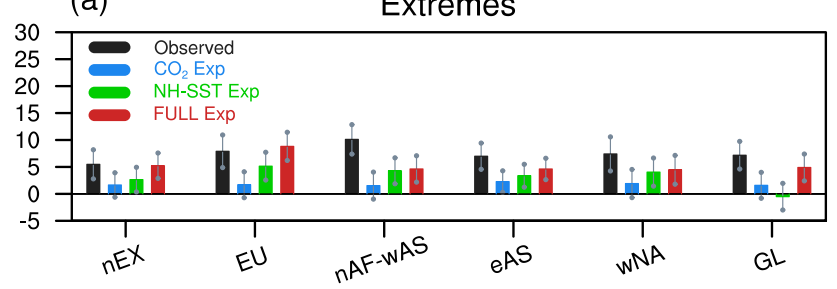

(c)

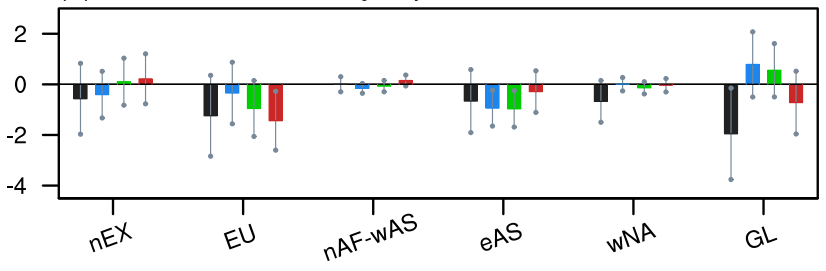

(e)

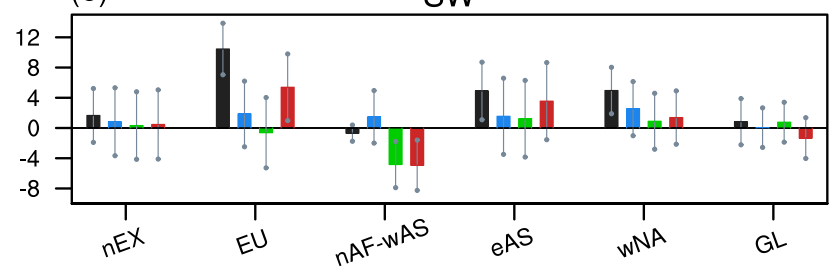

Fig. 3 a Observed and simulated anomalies of total number of days of hot extremes (days) averaged over the northern extratropics and five key regions (over land). b-f Same as in a, but for geopotential height at $300 \mathrm{hPa}(\mathrm{m})$, synoptic EKE at $300 \mathrm{hPa}\left(\mathrm{m}^{2} \mathrm{~s}^{-2}\right)$, total-cloud cover, $\mathrm{SW}\left(\mathrm{W} \mathrm{m}^{-2}\right)$, and $\mathrm{LW}\left(\mathrm{W} \mathrm{m}^{-2}\right)$, respectively. The $5 \%$ signifi-

\subsection{Role of the NH SST Change}

In this section, we investigate the role of SST in hot extremes. Figure 1c shows that the largest SST anomaly (difference between the late and early periods) occurs over the $\mathrm{NH}\left(10^{\circ}-70^{\circ} \mathrm{N}, 0^{\circ}-360^{\circ}\right)$, especially for $15^{\circ}-50^{\circ} \mathrm{N}$ and $40^{\circ}-65^{\circ} \mathrm{N}$ over the Pacific and Atlantic, respectively. It is interesting to note that the early period (1979-1995) corresponds to the positive and negative phases of the Pacific Decadal Oscillation (PDO) and AMO, respectively, while the late period (2002-2018) is associated with the opposite phases. Moreover, the role of SST over this region (i.e., $\left.10^{\circ}-70^{\circ} \mathrm{N}, 0^{\circ}-360^{\circ}\right)$ in hot extremes is not as known as that over the entire Pacific or Atlantic (e.g., Johnson et al. 2018) and tropics (e.g., Kosaka and Xie 2013). Thus, we focus on the impact of the NH SST on the hot extremes.

We conduct an experiment by changing SST over $10^{\circ}-70^{\circ} \mathrm{N}, 0^{\circ}-360^{\circ}$ with constant $\mathrm{CO}_{2}$ concentration $(\mathrm{NH}-$ SST Exp). The NH-SST Exp exhibits a positive hot extremes anomaly over northern mid-latitudes $\left(20^{\circ}-60^{\circ} \mathrm{N}\right)(\mathrm{Fig} .2 \mathrm{c})$, especially over four key regions (except for Greenland). Compared to the result in the $\mathrm{CO}_{2} \mathrm{Exp}$, the pattern of hot

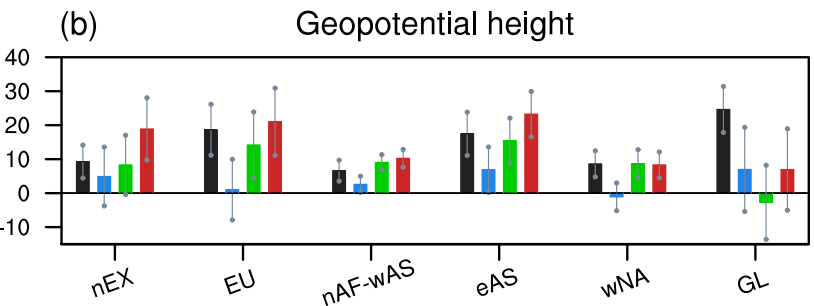

(d)

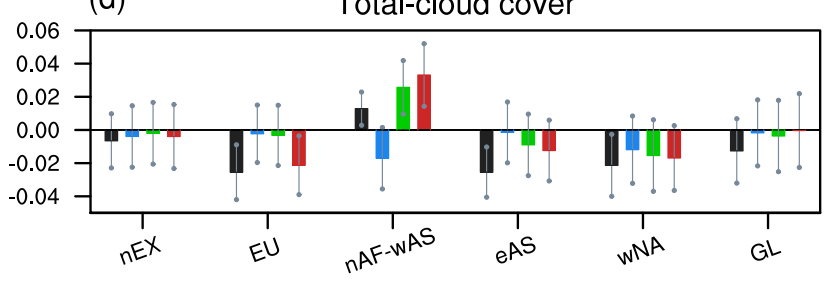

(f) LW

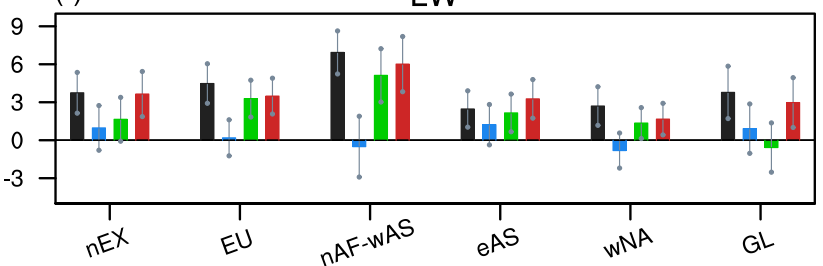

cant level according to the Student's $t$-test is denoted by error bars. $\mathrm{nEX}$, northern extratropics; EU, Europe; nAF-wAS, northern Africawestern Asia; eAS, eastern Asia; wNA, western North America; GL, Greenland

extremes anomaly in the NH-SST Exp is much closer to the observed pattern. The domain averaged hot extremes anomaly in the NH-SST Exp is also closer to the observation (Fig. 3a). It is also noted that the hot extremes anomaly over mid-latitudes (e.g., Europe, eastern Asia, and western North America) is better simulated compared to that over high-latitudes (e.g., Greenland).

Furthermore, the NH-SST Exp generally well simulates the mean and eddy flows over mid-latitudes, despite some discrepancies over the Pacific-North American sector (Fig. 4c). In particular, the high pressure and low EKE anomalies over Europe and eastern Asia are well captured by the model. Varying degrees of accuracy are shown for clouds and surface downward radiations (Figs. 5c and 6c). For example, the negative anomaly of the total-cloud over the eastern Asia and western North America, and positive anomaly over the northern Africa-western Asia are well simulated, but the large magnitude of negative anomaly over Europe is underestimated (Fig. 5c). As SW is linked to total-cloud cover, similar representation could be found for SW. The observed positive LW anomaly over the northern Africa-western Asia is also well captured by the NH-SST 
Fig. 4 a Difference in geopotential height (shading; $m$ ) and synoptic EKE (contours; $\mathrm{m}^{2} \mathrm{~s}^{-2}$ ) anomalies at $300 \mathrm{hPa}$ between the late and early periods in the observation. b-d Same as in a, but between the late and early run in three sets of the CAM5 simulations. Red solid and blue dashed lines represent the positive $\left(1.5\right.$ and $\left.4.0 \mathrm{~m}^{2} \mathrm{~s}^{-2}\right)$ and negative values $(-1.5$ and -4.0 $\left.\mathrm{m}^{2} \mathrm{~s}^{-2}\right)$, respectively

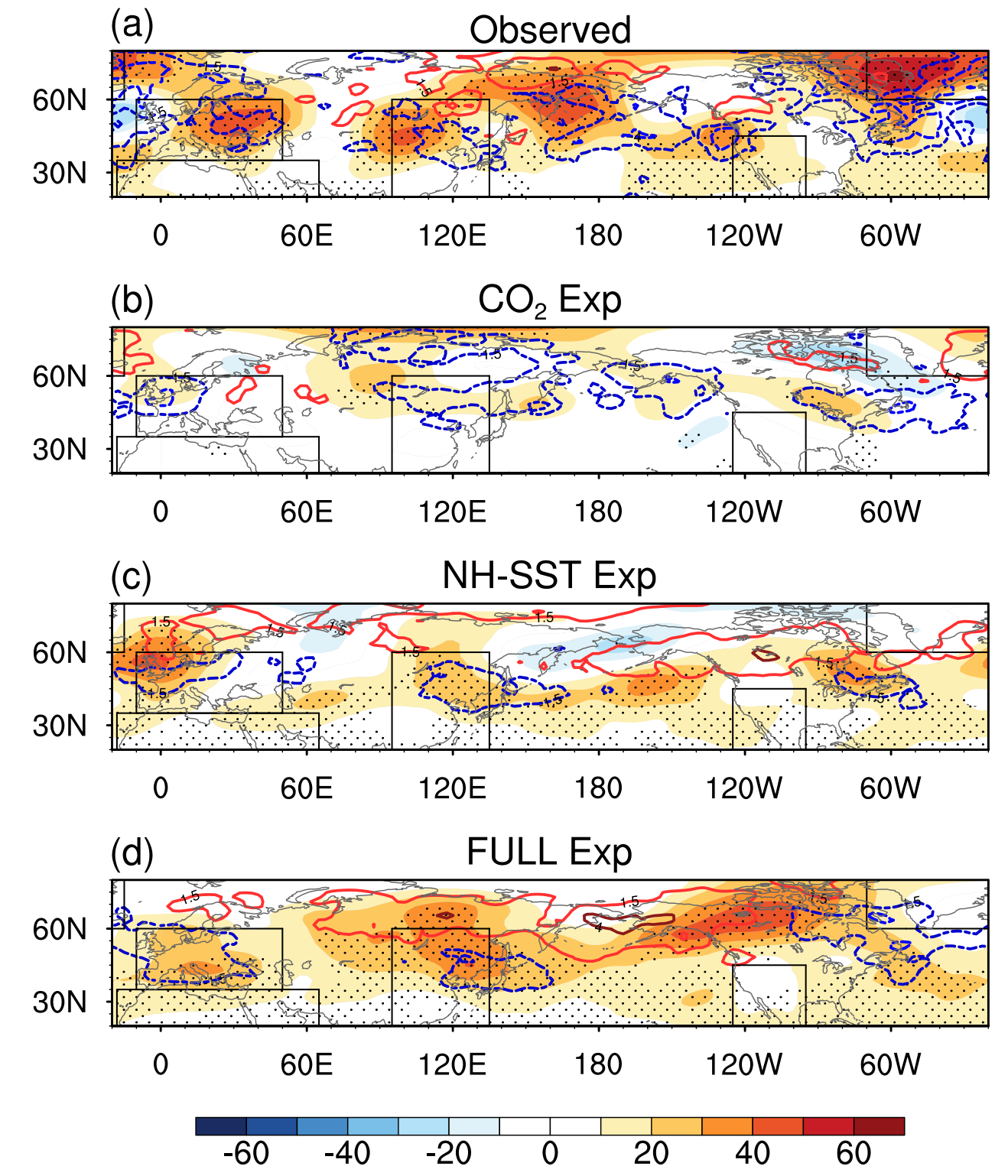

Exp. For the domain averaged variables, their signs are generally same as those in the observation despite their magnitudes are smaller (Fig. 3). These results suggest that the $\mathrm{NH}$ SST (mainly over $10^{\circ}-70^{\circ} \mathrm{N}$ ) is able to trigger hot extremes anomaly similar to that observed, as well as a good representation of dynamic and thermodynamic factors.

\subsection{Combined Effects of the NH SST and $\mathrm{CO}_{2}$}

The experiment with both $\mathrm{NH}$ SST and $\mathrm{CO}_{2}$ concentration changes (FULL Exp) shows a more similar pattern of hot extremes change compared to that of the single-change experiments, especially over high-latitudes (e.g., Greenland) (Fig. 2d). Figure 3a shows that the domain averaged anomaly of hot extremes days in the FULL Exp $(5.5 \pm 2.7$ days $)$ is very close to that observed $(5.2 \pm 2.4$ days $)$ over the northern extratropics. This result indicates the effectiveness of the decomposition of the total contribution into $\mathrm{CO}_{2}$ change and SST change. Compared to Johnson et al. (2018) that applies a coupled GCM with nudged SST, the FULL Exp with the combined SST and $\mathrm{CO}_{2}$ changes shows a more similar pattern to the observed hot extremes change over the northern Africa-western Asia and Greenland. Such similarity is likely to be reflected by prescribing the observed SST change over the NH oceans (where the largest SST anomaly occurs) in the AGCM.

Consistent with the result of the hot extremes, the geopotential height anomaly is well simulated in the FULL Exp (except for Greenland), as well as the synoptic EKE anomaly (Fig. 4d). The circulation anomaly over the Aleutian Islands is well represented due to the incorporation of the $\mathrm{CO}_{2}$ change. Over Europe, eastern Asia, and western 
Fig. 5 a-d Same as in Fig. 4, but for total-cloud cover (shading) and SW (contours; $\mathrm{W} \mathrm{m}^{-2}$ ). Red solid and blue dashed lines represent the positive (4 and $10 \mathrm{~W} \mathrm{~m}^{-2}$ ) and negative values $\left(-4\right.$ and $\left.-10 \mathrm{~W} \mathrm{~m}^{-2}\right)$, respectively
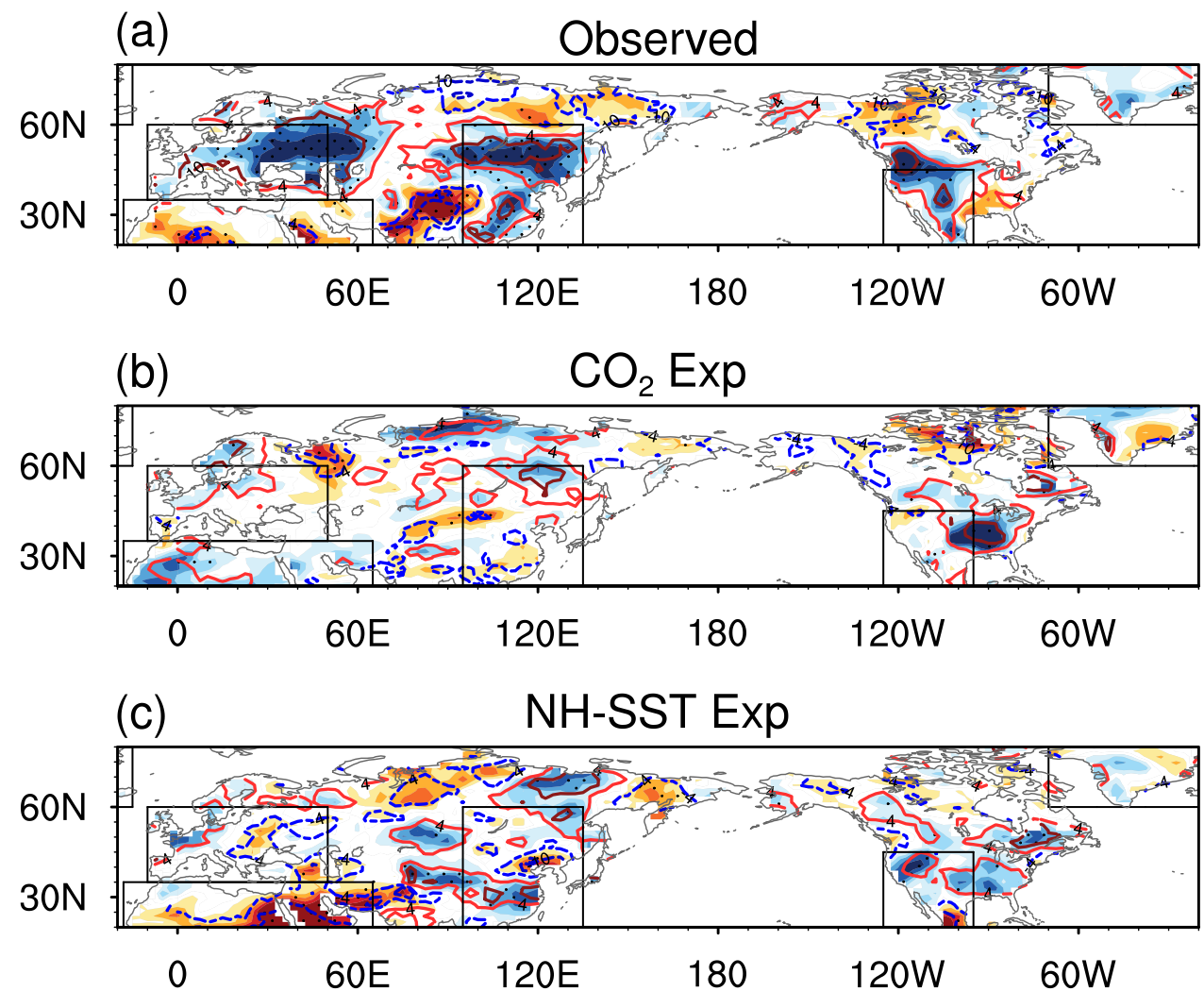

(d) FULL Exp

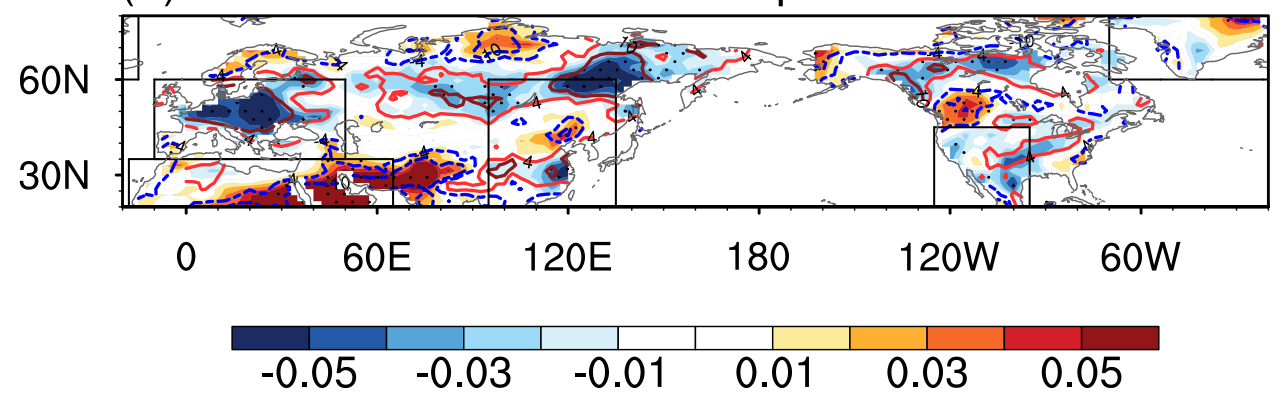

North America, the observed positive SW anomaly is linked to negative total-cloud cover anomaly (Figs. 5a and 6a), due to cloud albedo effect (NASA Facts 1999). The negative total-cloud cover and positive SW anomalies over these three key regions are well captured by the FULL Exp (Fig. 5d). In addition, the observed positive total-cloud cover anomaly over the northern Africa-western Asia and Green land leads to the large LW anomaly, due to cloud greenhouse effect (NASA Facts 1999). The large magnitude of LW anomaly over the northern Africa-western Asia could largely explain the hot extremes change there and such LW anomaly is well simulated by the FULL Exp (Fig. 6a, d). For the domain averaged variables, both signs and magnitudes are very similar to those in the observation (Fig. 3), further confirming effectiveness of the decomposition of the total contribution into $\mathrm{CO}_{2}$ change and $\mathrm{NH}$ SST change. Overall, our results show that the combined effects of the NH SST and $\mathrm{CO}_{2}$ can lead to more hot extremes in recent decades, similar to those observed. If it were not for the oceans' capacity to store the excess heat due to the rising $\mathrm{CO}_{2}$ concentration, the positive trend in hot extremes days would be substantially reduced (i.e., the results in the $\mathrm{CO}_{2} \mathrm{Exp}$ ).

\subsection{Role of other Possible Factors}

The aforementioned analyses suggest that SST over the $\mathrm{NH}$ (especially $10^{\circ}-70^{\circ} \mathrm{N}$ ) plays a significant role in hot extremes under global warming. To further understand individual roles of the North Pacific and North Atlantic, we conduct two experiments by changing SST over the North Pacific $\left(10^{\circ}-70^{\circ} \mathrm{N}, 110^{\circ} \mathrm{E}-100^{\circ} \mathrm{W}\right)$ and the North Atlantic $\left(10^{\circ}-70^{\circ} \mathrm{N}, 80 \mathrm{~W}^{\circ}-360^{\circ}\right)$, respectively (Table 2$)$. The 
Fig. 6 a-d Same as in Fig. 4, but for LW (shading; $\mathrm{W} \mathrm{m}^{-2}$ ) (a) Observed

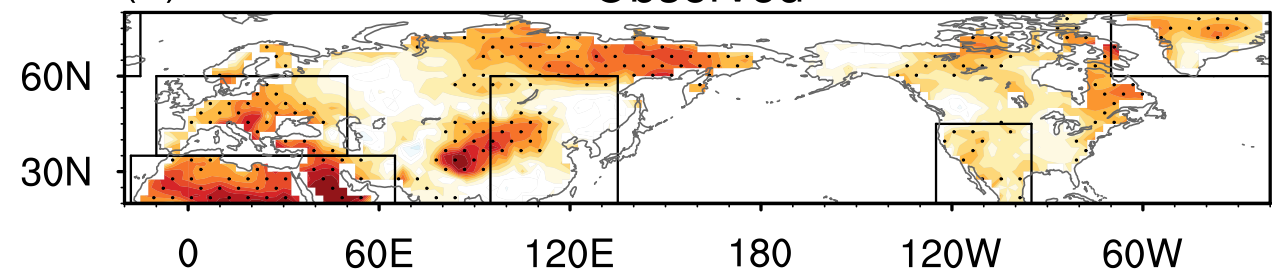

(b) $\mathrm{CO}_{2} \operatorname{Exp}$

$60 \mathrm{~N}$

$30 \mathrm{~N}$

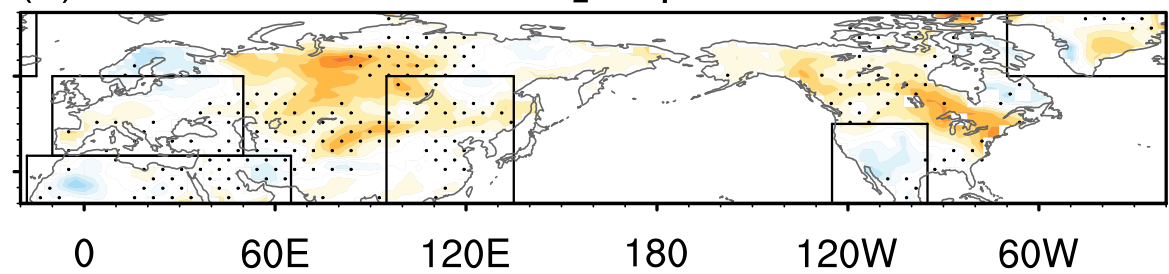

(c)

NH-SST Exp

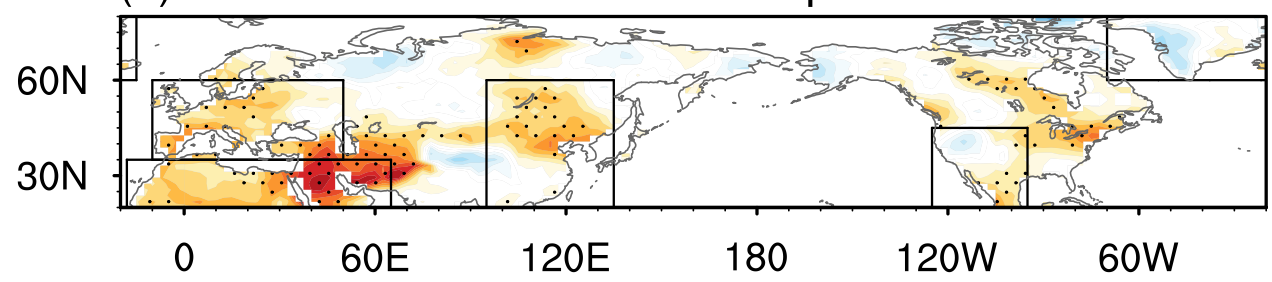

(d)

FULL Exp

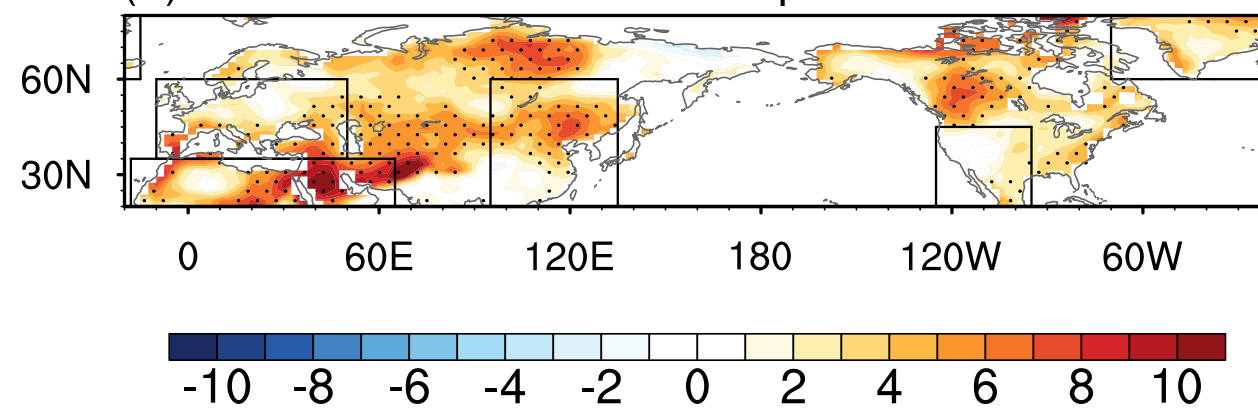

result shows that neither basin solely can capture the hot extremes change over mid-latitudes (Fig. 7a, b). For completeness, we further investigate the impact of the Arctic sea ice loss, which was found to be important for hot extremes over Europe (Zhang et al. 2020). From 1979 to 2018, there was a significant downward trend in the Arctic sea ice and such trend is linked to Arctic amplification (Coumou et al. 2018). We conduct the experiment by changing the SIC only (Table 2). The result shows that the SIC forcing well captures the increasing hot extremes over Europe but misrepresents changes over other key regions (Fig. 7c). In addition, the influence of the tropical SST on northern extratropical SAT has been documented (e.g., Kosaka and Xie 2013). We conduct the experiment by changing SST over the tropics $\left(20^{\circ} \mathrm{S}-20^{\circ} \mathrm{N}, 0^{\circ}-360^{\circ}\right)$ (Table 2$)$. Figure $7 \mathrm{~d}$ shows that the increasing hot extremes over the northern Africa-western Asia, western North America (lower latitudes), eastern Asia, and Greenland are well captured by the model, while the magnitude of such change over the last two regions is much smaller than that in the observation. Overall, the additional experiments suggest that the hot extremes change simulated by changing North Pacific (or Atlantic) or Arctic SIC is not as significant as that in the observation, while tropical SST is also an important factor for the hot extremes change.

As mentioned in previous sections, we focus on and prescribe the SST anomaly over the $\mathrm{NH}$ (especially $10^{\circ}-70^{\circ} \mathrm{N}$ ) 
Table 2 List of five additional CAM5 experiments. Each experiment includes an early run, a transition run, and a late run. "Clm" denotes climatology of 1979-2018 and 1950-2018 for the first four experiments and the fifth experiment, respectively

\begin{tabular}{|c|c|c|c|c|c|}
\hline Experiments & Runs & Ensembles & SST & SIC & $\mathrm{CO}_{2}$ \\
\hline \multirow[t]{3}{*}{ North_Pacific-SST Exp } & Early & 17 & Clm + North Pacific SST anomaly (early) & $\mathrm{Clm}$ & Clm \\
\hline & Transition & 6 & Clm & $\mathrm{Clm}$ & Clm \\
\hline & Late & 17 & Clm + North Pacific SST anomaly (late) & $\mathrm{Clm}$ & Clm \\
\hline \multirow[t]{3}{*}{ North_Atlantic-SST Exp } & Early & 17 & $\mathrm{Clm}+$ North Atlantic SST anomaly (early) & $\mathrm{Clm}$ & Clm \\
\hline & Transition & 6 & Clm & $\mathrm{Clm}$ & Clm \\
\hline & Late & 17 & Clm + North Atlantic SST anomaly (late) & $\mathrm{Clm}$ & Clm \\
\hline \multirow[t]{3}{*}{ SIC Exp } & Early & 17 & $\mathrm{Clm}$ & Clm + SIC anomaly (early) & Clm \\
\hline & Transition & 6 & Clm & $\mathrm{Clm}$ & Clm \\
\hline & Late & 17 & $\mathrm{Clm}$ & Clm + SIC anomaly (late) & $\mathrm{Clm}$ \\
\hline \multirow[t]{3}{*}{ Tropical-SST Exp } & Early & 17 & $\mathrm{Clm}+$ tropical SST anomaly (early) & $\mathrm{Clm}$ & $\mathrm{Clm}$ \\
\hline & Transition & 6 & Clm & Clm & $\mathrm{Clm}$ \\
\hline & Late & 17 & Clm + tropical SST anomaly (late) & Clm & $\mathrm{Clm}$ \\
\hline \multirow[t]{3}{*}{ NH-SST Exp (1950-2018) } & Early & 30 & Clm + NH SST anomaly (early, 1950-1979) & Clm & Clm \\
\hline & Transition & 9 & Clm & $\mathrm{Clm}$ & $\mathrm{Clm}$ \\
\hline & Late & 30 & $\begin{array}{l}\text { Clm + NH SST anomaly } \\
\text { (late, 1989-2018) }\end{array}$ & Clm & $\mathrm{Cl}_{1}$ \\
\hline
\end{tabular}

Fig. 7 a-d Difference in the total number of days of hot extremes (shading; days) between the late and early run in four sets of additional CAM5 experiments (for the period of 1979-2018). Stippling indicates regions significant at the 5\% level according to the Student's $t$-test. Black boxes indicate the five key regions (a) North_Pacific-SST Exp

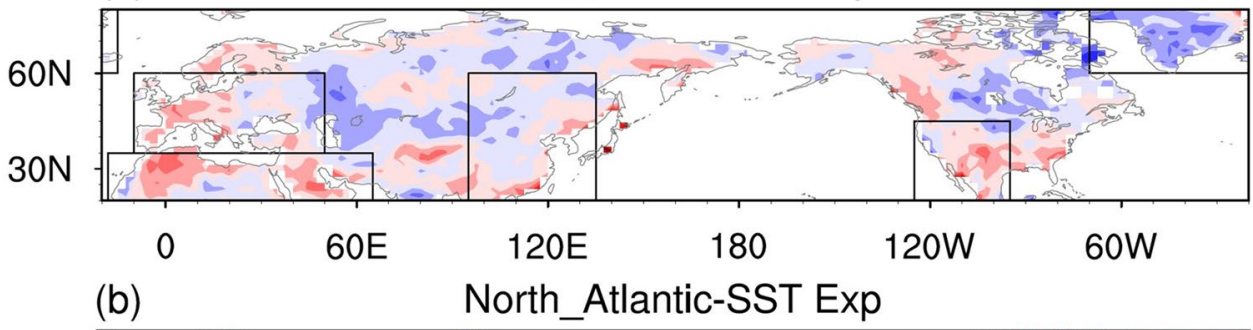

$60 N$

$30 N$

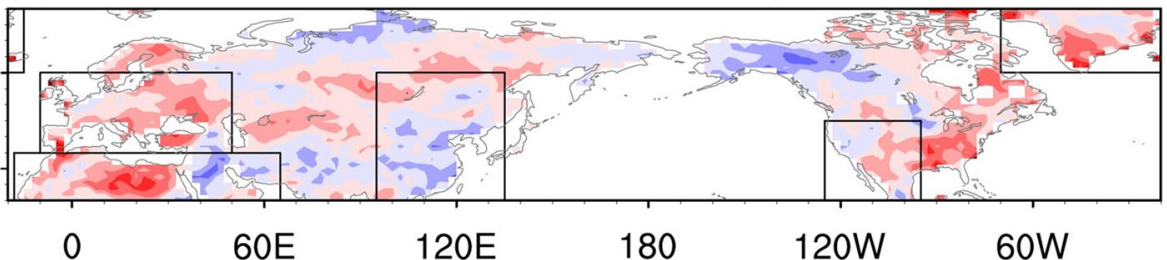

(c) SIC Exp

$60 \mathrm{~N}$

$30 \mathrm{~N}$

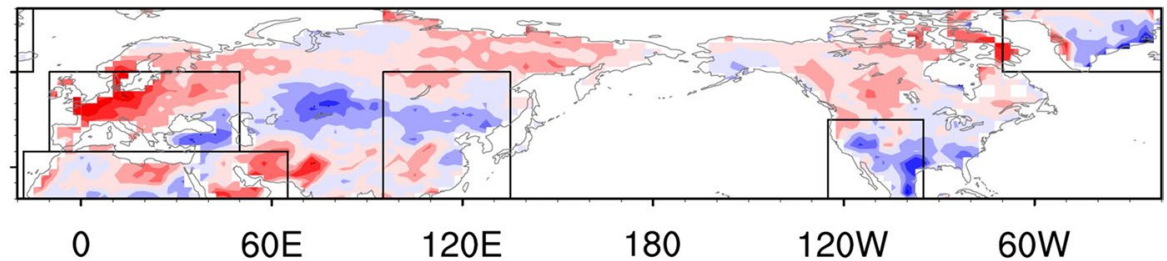

(d)

Tropical-SST Exp

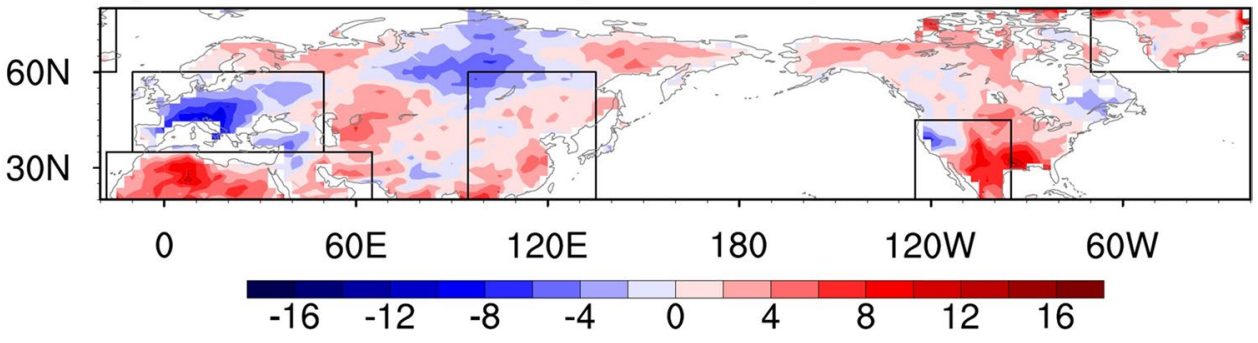


because 1) the largest SST anomaly (i.e., difference between the late and early periods) occurs over this region (Fig. 1a) and 2) the role of SST over this region is not as known as that over the entire Pacific or Atlantic (e.g., Johnson et al. 2018) and tropics (e.g., Kosaka and Xie 2013). Despite the significant role of the NH SST warming, the source for the SST warming is still unclear. Previous studies have suggested that the change in SST is related to both anthropogenic forcing (e.g., $\mathrm{CO}_{2}$ concentration rising) and natural variability (Meehl et al. 2009, 2013; Chan and Wu 2015; Hua et al. 2018; Liguori et al. 2020). In the current studying period (1979-2018), the early period corresponds to the positive and negative phases of the PDO and AMO, respectively, while the late period is linked to the opposite phases. It is uncertain whether the hot extremes change is caused by the phase change of the oceanic modes or the warming trend of SST (due to anthropogenic forcing).

To better estimate the effect of anthropogenic forcing (i.e., warming trend) versus natural variability (i.e., phase change of PDO and AMO), we analyze observational data and conduct an experiment for a longer period (1950-2018). The early and late periods are defined as 1950-1979 and 1989-2018, respectively, with a transition period during $1980-1988$. Note that the period of $1950-1979$ or 1989-2018 is not associated with a single phase of those oceanic modes (e.g., PDO and AMO) and thus we may better understand the role of anthropogenic forcing (i.e., warming trend). In the observation, in contrast to Fig. 2a, there are less hot extremes in the late period (1989-2018) over the northern Africa-western Asia and eastern Asia (Fig. 8a). Then, we conduct an experiment by changing SST over $10^{\circ}-70^{\circ} \mathrm{N}, 0^{\circ}-360^{\circ}$ for $1950-1979$ and $1989-2018$ (Table 2). The hot extremes pattern for the NH-SST Exp with the longer period shares some similarities with that in the observation, especially less hot extremes during the late period over the northern Africa-western Asia and eastern Asia (Fig. 8b). Without the influence of the phase change of oceanic modes, the increasing hot extremes over these two keys regions is not shown for the analysis with the longer period. This result indicates that the increasing hot extremes over these two regions (shown in Fig. 2a, c) are probably associated with the certain time period (i.e., 1979-2018) and the influence of the phase change of oceanic modes during this period. For other key regions, both anthropogenic forcing (warming trend) and natural variability (phase change of PDO and AMO) play a role in the increasing hot extremes.

\section{Concluding Remarks}

This study investigates possible causes for the increasing hot extremes over the northern extratropics during summer. The past four decades have seen an increase of hot extremes, accompanied by the NH SST warming and $\mathrm{CO}_{2}$ concentration rising. Through a series of modeling experiments with the CAM5 model, we show that the increase of hot extremes is largely due to these two factors. However, the rising $\mathrm{CO}_{2}$ concentration alone cannot trigger the observed change of hot extremes days, as well as mean and eddy flows, clouds, and surface downward radiations, due to the lack of SST adjustment. Due to the oceans' capacity to store a large amount of heat in the Earth system, the incorporation of the NH SST change strengthens terrestrial warming over the northern extratropics, as shown by capturing anomalies of hot extremes days and those dynamic and thermodynamic factors. Specifically, over Europe, eastern Asia, and western North America, the experiment with both NH SST and $\mathrm{CO}_{2}$ concentration changes (FULL Exp) well simulates
Fig. 8 a Difference in the total number of days of hot extremes (shading; days) between the late (1989-2018) and early (1950-1979) period in the observation (using NCEPNCAR reanalysis data) for the period of 1950-2018. b Same as in $\mathbf{a}$, but between the late and early run in CAM5 NH-SST experiments (for the period of 1950-2018). Stippling indicates regions significant at the 5\% level according to the Student's $t$-test. Black boxes indicate the five key regions

\section{(a) Observed (1950-2018)}
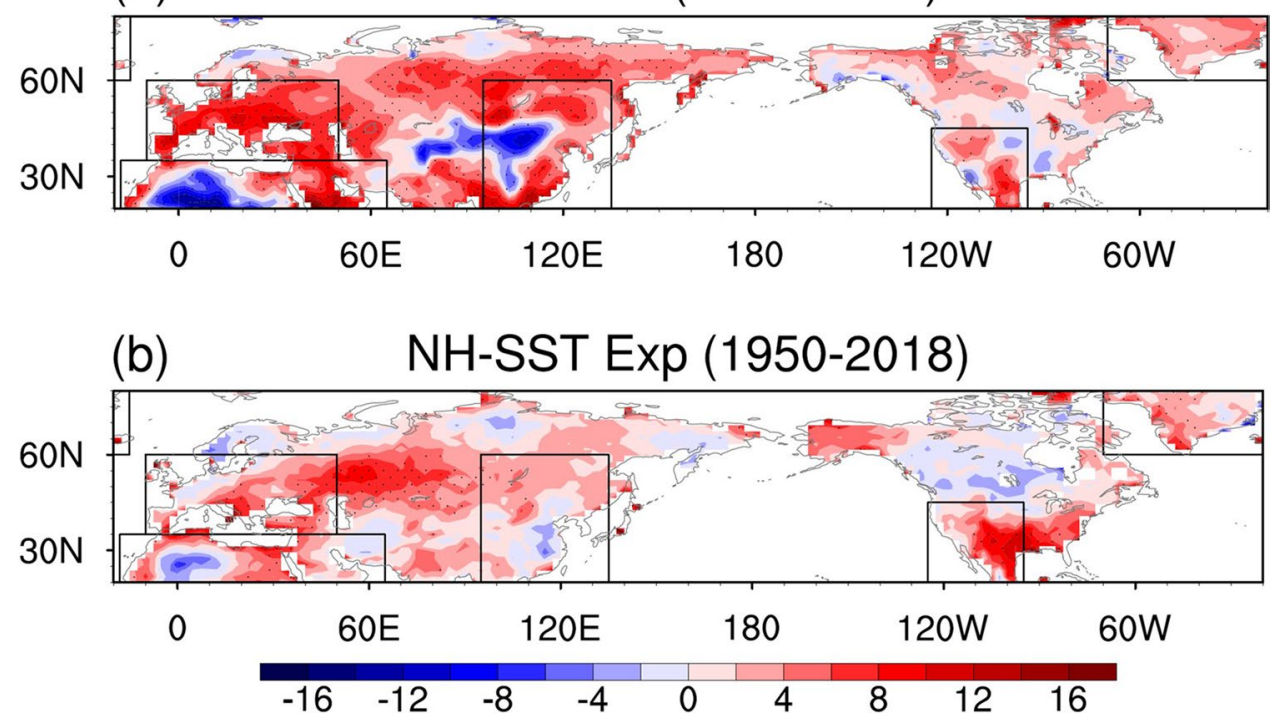
SW radiation, which is modulated by total-cloud cover and eddy-mean flows. Over the northern Africa-western Asia and Greenland, the FULL Exp faithfully captures LW radiation, which is responsible for the increasing hot extremes over these two regions. Finally, our study discusses potential roles of natural variability (e.g., PDO and AMO) and other possible factors (e.g., Arctic sea ice and tropical SST).

One caveat of the current study is that the modeling setting in the CAM5 experiments cannot really disentangle the individual roles of the $\mathrm{NH} \mathrm{SST}$ and $\mathrm{CO}_{2}$ because the change in SST is related to both anthropogenic forcing and natural variability (Meehl et al. 2009, 2013; Chan and Wu 2015; Hua et al. 2018; Liguori et al. 2020). To fully exclude the effects of $\mathrm{CO}_{2}$ on SST, one might need to design an experiment where SST evolves freely and $\mathrm{CO}_{2}$ concentration remains fixed. Such an experiment is part of our ongoing and future works. Despite the caveat, this study truly highlights the importance of the NH oceans (especially over the extratropics) to the northern extratropical hot extremes under global warming. In addition, this study only analyzes outputs of the CAM5 model and model dependency may influence the results. Conducting modeling experiments using different models is encouraged for future studies.

Acknowledgements We thank the two anonymous reviewers for their insightful comments. We also thank comments from Prof. Rong Fu, Prof. Robert E. Dickinson, and Dr. Ping Zhao for an early version of the manuscript. Thank Prof. Rong Fu for providing postdoctoral support for SZ.

Funding This study is supported by Fund Project of Collaborative Innovation in Science and Technology in Bohai-rim Region (QYXM201904) and Forecaster Special Project of China Meteorological Administration (CMAYBY2020-071).

Data Availability The ERA5 reanalysis data are available in https:// cds.climate.copernicus.eu/cdsapp\#!/home. The NCEP-NCAR reanalysis data are from https://psl.noaa.gov/data/gridded/data.ncep.reana lysis.html. The HadISST data are from https://www.metoffice.gov.uk/ hadobs/hadisst/. The global mean $\mathrm{CO}_{2}$ concentration is from https:// www.esrl.noaa.gov/gmd/ccgg/trends/global.html\#global_data. The outputs of CAM5 model experiments are available in http://doi.org/ 10.5281/zenodo.4023295.

Code Availability The code is available from S. Zhao upon request.

\section{Declarations}

Competing Interests The authors declare no competing interests.

Open Access This article is licensed under a Creative Commons Attribution 4.0 International License, which permits use, sharing, adaptation, distribution and reproduction in any medium or format, as long as you give appropriate credit to the original author(s) and the source, provide a link to the Creative Commons licence, and indicate if changes were made. The images or other third party material in this article are included in the article's Creative Commons licence, unless indicated otherwise in a credit line to the material. If material is not included in the article's Creative Commons licence and your intended use is not permitted by statutory regulation or exceeds the permitted use, you will need to obtain permission directly from the copyright holder. To view a copy of this licence, visit http://creativecommons.org/licenses/by/4.0/.

\section{References}

Baker, H.S., et al.: Higher $\mathrm{CO}_{2}$ concentrations increase extreme event risk in a $1.5^{\circ} \mathrm{C}$ world. Nat. Clim. Change 8, 604-608 (2018)

Chan, D., Wu, Q.: Attributing observed SST trends and subcontinental land warming to anthropogenic forcing during 1979-2005. J. Clim. 28, 3152-3170 (2015)

Ciais, P., Reichstein, M., et al.: Europe-wide reduction in primary productivity caused by the heat and drought in 2003. Nature 437, 529-533 (2005)

Copernicus Climate Change Service: ERA5: Fifth generation of ECMWF atmospheric reanalyses of the global climate. Copernicus Climate Change Service Climate Data Store (CDS). (2017). https://cds.climate.copernicus.eu/cdsapp\#!/home. Accessed 18 Apr 2019

Coumou, D., Rahmstorf, S.: A decade of weather extremes. Nat. Clim. Change 2, 491-496 (2012)

Coumou, D., Lehmann, J., Beckmann, J.: The weakening summer circulation in the Northern Hemisphere mid-latitudes. Science 348, 324-327 (2015)

Coumou, D., Capua, G.D., Vavrus, S., Wang, L., Wang, S.: The influence of Arctic amplification on mid-latitude summer circulation. Nat. Commun. 9, 2959 (2018)

Dai, A., Fyfe, J.C., Xie, S.P., Dai, X.: Decadal modulation of global surface temperature by internal climate variability. Nat. Clim. Change 5, 555-559 (2015)

Dai, A., Bloecker, C.E.: Impacts of internal variability on temperature and precipitation trends in large ensemble simulations by two climate models. Clim. Dyn. 52, 289-306 (2019)

Deser, C., Phillips, A.S.: Atmospheric circulation trends, 1950-2000: The relative roles of sea surface temperature forcing and direct atmospheric radiative forcing. J. Clim. 22, 396-413 (2009)

Ding, Q.H., Wang, B.: Circumglobal teleconnection in the Northern Hemisphere summer. J. Clim. 18, 3483-3505 (2005)

Fernando, D.N., Mo, K.C., Fu, R., et al.: What caused the spring intensification and winter demise of the 2011 drought over Texas? Clim. Dyn. 47, 3077-3090 (2016)

Gao, M., Yang, J., Gong, D., Shi, P., Han, Z., Kim, S.: Footprints of Atlantic multidecadal oscillation in the low-frequency variation of extreme high temperature in the Northern Hemisphere. J. Clim. 32, 791-802 (2019)

Grise, K., Polvani, L.M.: The response of midlatitude jets to increased $\mathrm{CO}_{2}$ : distinguishing the roles of sea surface temperature and direct radiative forcing. Geophys. Res. Lett. 41, 6863-6871 (2014)

Horton, R.M., Mankin, J.S., Lesk, C., Coffel, E., Raymond, C.: A review of recent advances in research on extreme heat events. Curr. Clim. Change Rep. 2, 242-259 (2016)

Hua, W., Dai, A., Qin, M.: Contributions of internal variability and external forcing to the recent pacific decadal variations. Geophy. Res. Lett. 45, 7084-7092 (2018)

Jaeger, E.B., Seneviratne, S.I.: Impact of soil moisture-atmosphere coupling on European climate extremes and trends in a regional climate model. Clim. Dyn. 36, 1919-1939 (2011)

Johnson, N.C., Xie, S.P., Kosaka, Y., Li, X.: Increasing occurrence of cold and warm extremes during the recent global warming slowdown. Nat. Commun. 9, 1724 (2018) 
Kalnay, E., et al.: The NCEP/NCAR 40-year reanalysis project. Bull. Am. Meteorol. Soc. 77, 437-471 (1996)

Kosaka, Y., Xie, S.P.: Recent global-warming hiatus tied to equatorial Pacific surface cooling. Nature 501, 403-407 (2013)

Lee, M.H., Lee, S., Song, H.J., Ho, C.H.: The recent increase in the occurrence of a boreal summer teleconnection and its relationship with temperature extremes. J. Clim. 30, 7493-7504 (2017)

Lenderink, G., van Ulden, A., van den Hurk, B., van Meijgaard, E.: Summertime inter-annual temperature variability in an ensemble of regional model simulations: Analysis of the surface energy budget. Clim. Change 81, 233-247 (2007)

Liguori, G., McGregor, S., Arblaster, J.M., et al.: A joint role for forced and internally-driven variability in the decadal modulation of global warming. Nat. Commun. 11, 3827 (2020)

Luo, L.F., Zhang, Y.: Did we see the 2011 summer heat wave coming? Geophys. Res. Lett. 39, L09708 (2012)

Ma, S., Zhou, T., Stone, D.A., Angélil, O., Shiogama, H.: Attribution of the July-August 2013 heat event in Central and Eastern China to anthropogenic greenhouse gas emissions. Environ. Res. Lett. 12, 054020 (2017)

Mak, M., Zhao, S., Deng, Y.: Charney Problem with a Generic Stratosphere. J. Atmos. Sci. 78, 1021-1037 (2021)

Meehl, G.A., Hu, A., Santer, B.D.: The mid-1970s climate shift in the Pacific and the relative roles of forced versus inherent decadal variability. J. Clim. 22, 780-792 (2009)

Meehl, G.A., Hu, A., Arblaster, J.M., Fasullo, J., Trenberth, K.E.: Externally forced and internally generated decadal climate variability associated with the Interdecadal Pacific Oscillation. J. Clim. 26, 7298-7310 (2013)

NASA Facts: Clouds and energy cycle Technical Report NF-207, NASA, Goddard Space Flight Center, Maryland, USA (1999)

Neale, R.B. et al: Description of the NCAR Community Atmosphere Model (CAM 5.0). NCAR Tech. Note, NCAR/TN-486+STR (2012)

Perkins-Kirkpatrick, S.E., Lewis, S.C.: Increasing trends in regional heatwaves. Nat. Commun. 11, 3357 (2020)

Rayner, N.A., Parker, D.E., Horton, E.B., Folland, C.K., Alexander, L.V., Rowell, D.P., Kent, E.C., Kaplan, A.: Global analyses of sea surface temperature, sea ice, and night marine air temperature since the late nineteenth century. J. Geophys. Res. 108, 4407 (2003)

Röthlisberger, M., Martius, O.: Quantifying the local effect of northern hemisphere atmospheric blocks on the persistence of summer hot and dry spells. Geophys. Res. Lett. 46, 10101-10111 (2019)

Schär, C., Jendritzky, G.: Hot news from summer 2003. Nature 432, 559-560 (2004)

Shaw, T.A., Voigt, A.: Tug of war on the summertime circulation between radiative forcing and sea surface warming. Nat. Geosci. 8, 560-566 (2015)

Shaw, T.A., Voigt, A.: Land dominates the regional response to $\mathrm{CO}_{2}$ direct radiative forcing. Geophys. Res. Lett. 43, 11383-11391 (2016)
Sousa, P.M., Trigo, R.M., Barriopedro, D., Soares, P.M.M., Santos, J.A.: European temperature responses to blocking and ridge regional patterns. Clim. Dyn. 50, 457-477 (2018)

Stolpe, M.B., Medhaug, I., Knutti, R.: Contribution of Atlantic and Pacific multidecadal variability to twentieth-century temperature changes. J. Clim. 30, 6279-6295 (2017)

Su, Q., Dong, B.: Recent decadal changes in heat waves over China: Drivers and mechanisms. J. Clim. 32, 4215-4234 (2019)

Sun, Y., Song, L., Yin, H., Zhou, B., Hu, T., Zhang, X., Stott, P.: Human influence on the 2015 extreme high temperature events in western China. Bull. Amer. Meteor. Soc. 97, S102-S106 (2016)

Teng, H., Branstator, G., Wang, H., Meehl, G., Washington, W.: Probability of US heat waves affected by a subseasonal planetary wave pattern. Nat. Geosci. 6, 1056-1061 (2013)

Tian, F., Dong, B., Robson, J., Sutton, R., Wilcox, L.: Processes shaping the spatial pattern and seasonality of the surface air temperature response to anthropogenic forcing. Clim. Dyn. 54, 3959-3975 (2020)

Trenberth, K., Fasullo, J.T., Shepherd, T.G.: Attribution of climate extreme events. Nat. Clim. Change 5, 725-730 (2015)

von Schuckmann, K., et al.: Heat stored in the Earth system: Where does the energy go? Earth Syst. Sci. Data 12, 2013-2041 (2020)

Watanabe, M., et al.: Contribution of natural decadal variability to global warming acceleration and hiatus. Nat. Clim. Change 4, 893-897 (2014)

Xie, S.P., et al.: Towards predictive understanding of regional climate change. Nat. Clim. Change 5, 921-930 (2015)

Zhang R, Sun C, Zhu J, Zhang R, Li W (2020) Increased European heat waves in recent decades in response to shrinking Arctic sea ice and Eurasian snow cover. npj Clim. Atmos. Sci. 3, 7

Zhao, S., Deng, Y., Black, R.X.: Observed and simulated spring and summer dryness in the United States: The impact of the Pacific sea surface temperature and beyond. J. Geophys. Res. Atmos. 122, 12,713-12,731 (2017)

Zhao, S., Deng, Y., Black, R.X.: An intraseasonal mode of atmospheric variability relevant to the U.S. hydroclimate in boreal summer: Dynamic origin and East Asia connection. J. Clim. 31, 9855-9868 (2018)

Zhao, S., Deng, Y., Li, W.: A nonmodal instability perspective of the declining northern mid-latitude synoptic variability in boreal summer. J. Clim. 33, 1177-1192 (2020)

Zhao, S., Deng, Y.: Nonmodal growth of atmospheric disturbances relevant to the East Asian pressure surge in boreal winter. Clim. Dyn. 54, 3077-3089 (2020)

Publisher's Note Springer Nature remains neutral with regard to jurisdictional claims in published maps and institutional affiliations. 